\title{
Effects of Age, Spatial Relation and Object Type on Young Children's Analogical Transfer of Spatial Relations
}

\author{
Youjeong Park \\ Assistant Professor, Department of Child Development and Family Studies, Seoul National University, Seoul, Korea \\ 연령, 공간관계 및 제시물 유형이 유아의 유추적 전이 수행에 미치는 효과 \\ 박유정 \\ 서울대학교 아동가족학과 조교수
}

\begin{abstract}
Objectives: This study tested four- and five-year-old children's analogical transfer of spatial relations from samples consisting of either richly decorated geometric shapes or concrete objects. It also examined whether young children would transfer containment relations more readily than they would transfer support relations, and whether the difference between children's transfer of containment and support relations would vary with object type and age.

Methods: Four- and five-year-old children $(N=73)$ recruited in Busan were presented with a spatial analogies task adopted from Huttenlocher and Levine (1990). Children were asked to transfer containment and support relations from samples consisting of either richly decorated geometric shapes or concrete objects, to three choices consisting of concrete objects.

Results: First, four-year-olds successfully transferred containment relations only from concrete objects, whereas five-year-olds did so from both types of objects. Second, four-year-olds failed to transfer support relations regardless of object type, whereas five-year-olds successfully transferred support relations from richly decorated geometric shapes. Third, five-year-olds overall showed better performance than fouryear-olds. Finally, children transferred containment relations more readily than they transferred support relations only when the samples consisted of concrete objects (but not when the samples were geometric shapes).

Conclusion: The results suggest that children's transfer of spatial relations overall improves between ages four and five years and that young children's transfer of support relations (less salient spatial relations than containment) may benefit from the use of geometric shapes.
\end{abstract}

Keywords: analogical transfer, containment, support, geometric shapes, concrete objects

\section{Introduction}

유추(analogy)는 한 사례의 관계적 구조를 다른 사례로 전이 (transfer)시키는 사고(Gentner, 1983; Vosniadou, 1989)로서, 인 간의 중요한 인지적 도구 중 하나이다. 유추 능력 덕분에 우리

Corresponding Author: Youjeong Park, Assistant Professor, Department of Child Development \& Family Studies, Seoul National University, 1 Gwanak-ro, Gwanak-gu, Seoul, Korea

E-mail: youjeongpark@snu.ac.kr
는 '원숭이와 바나나'의 관계를 '고양이와 생선'의 관계와 같다 고 인식하고, 뇌의 시냅스에서 일어나는 변화를 정원사의 가 지치기에 비유해 이해한다. 또한, 초콜릿이 초콜릿 상자 안에 들어있는 상황과 연필이 필통 안에 들어있는 상황을 동일한 관계적 구조(relational structure)를 지닌 것으로 인식하고, '포함

(C)The Korean Association of Child Studies

This is an Open Access article distributed under the terms of the Creative Commons Attribution Non-Commercial License (http:// creativecommons.org/licenses/by-nc/4.0) which permits unrestricted noncommercial use, distribution, and reproduction in any medium, provided the original work is properly cited. 
(한 물체가 다른 물체 안에 들어있는 관계)'이라는 추상적이고 관계적인 개념을 습득하며, '안', '들어있다'와 같은 어휘를 습 득한다. 뿐만 아니라, 유추는 낮선 문제 상황에 직면했을 때 기 존에 해결하였던 문제 상황과의 구조적 공통성에 근거해서 문 제를 해결할 수 있도록 한다(Holyoak, Junn, \& Billman, 1984; Tunteler \& Resing, 2002).

유추적 사고의 기제(mechanism)에 대해서는 여러 이론 적 주장이 있으나, 두 사례를 구성하는 요소들 간의 대응 (mapping)과, 기초가 되는 사례(base 또는 sample)에서 사물 간 의 관계적 구조를 인출(retrieval)하는 것이 유추적 사고과정 의 핵심요소로 지적되었다(Gentner, 1989; Pellegrino, 1985; Sternberg \& Gardner, 1983). 구체적으로, Gentner (1989)의 구 조적 맵핑 이론(structural mapping theory)에 의하면, 유추는 두 사례를 구성하는 사물들을 일대일 대응시키는 과정을 필수적 으로 포함한다. 예를 들어, '고양이:생선::원숭이:?'의 유추 문 제를 해결하기 위해서는 고양이를 원숭이에, 생선을 '?'에 대 응시키는 과정이 필요하다는 것이다. 한편, Pellegrino (1985), Stenberg와 Gardner (1983) 등은 사례 간의 대응이 일어나기 전 에 기초가 되는 사례에서 사물들 간의 관계를 파악하고 인출 하는 과정이 먼저 필요하다고 보았다. 예를 들어, 유아는 '고양 이:생선'을 보고 자신의 사전 지식을 바탕으로 고양이와 생선 의 관계는 동물과 그가 좋아하는 먹이의 관계라는 점을 기억 속에서 인출해야 한다는 것이다. 그리고 나서 이를 새로운 사 례인 '원숭이:?’에 적용하여 생선에 대응되는 것이 바나나임을 유추할 수 있다고 보았다.

이러한 유추 능력은 영아기부터 나타나지만(Ferry, Hespos, \& Gentner, 2015) 유아기에도 유추 성공 여부는 주어진 조 건에 의해 민감하게 영향을 받는다. 구체적으로, 4-6세 유아 는 비교되는 사례에서 관계적 역할이 동일한 사물 간의 표면 적 유사성이 낮은 경우 유추에 어려움을 겪는다(Gentner \& Toupin, 1986; Lowenstein \& Gentner, 2005; Richland, Morrison, $\&$ Holyoak, 2006). 또한, 관계의 복잡성이 증가하거나(예: 관계 를 구성하는 요소의 개수 증가) 친숙성이 낮은 경우에도 유추 수행에 어려움을 보인다(Goswami, 1989; Richland et al., 2006). 이처럼 유아의 유추가 주어진 조건에 의해 어떻게 영향을 받 는지 살펴보는 연구는 유추적 사고의 발달 과정을 이해하고 유아의 유추 능력 발달을 지원하는 방안을 마련하는 데 기초 자료를 제공한다. 이에 본 연구는 유아의 유추과제 수행에 영 향을 미치는 요인으로서 유아의 연령, 유추할 관계의 특성, 그 리고 제시물의 유형을 살펴보고자 한다.

유추 능력은 연령에 따라 향상되는 것으로 알려져 있으
며, 연구자들은 연령에 따른 유추 능력 향상의 원인으로 관계 적 지식의 축적(Gentner \& Rattermann, 1991), 유추 전략의 발 달(Starr, Vendetti, \& Bunge, 2018), 작업기억의 증가(Halford, 1993; Simms, Frausel, \& Richland, 2018), 정보 억제 능력을 포 함한 실행기능의 향상(Richland et al., 2006; Thibaut \& French, 2016; Thibaut, French, \& Vezneva, 2010) 등을 지적해 왔다. 유 아기 내에서도 유추 능력의 향상은 일어나는 것으로 보인 다. 이를 뒷받침하는 연구결과로, Goswami와 Brown (1990a) 의 연구에서 3 세, 4 세, 6 세 유아의 유추 문제 해결 능력이 연 령에 따른 향상을 보였고, 특히 3세와 4세 사이에 급격한 향 상이 나타났음을 들 수 있다. Holyoak와 Thagard (1995)도 4세 와 6세 사이에 표면적 유사성을 넘어 관계성을 고려한 체계적 맵핑(system mapping)이 가능해진다고 하였다. 또한, 세 개의 사물 간 상대적 위치의 유추적 전이를 조사한 Loewenstein과 Gentner (2005)의 연구에서도 3세의 45\%, 4 세의 $64 \%$ 가 유추 에 성공하였다. 사물 간의 기초적인 공간적 관계(어떤 사물이 다른 사물보다 상대적으로 위에 있는 관계, 사물이 다른 사물 바로 위에 놓인 관계, 사물이 다른 사물 안에 놓인 관계)를 유 추하는 능력을 조사한 연구에서, 3 세 유아는 전반적으로 유추 에 실패한 반면(Park, 2015), 4세 유아와 5세 유아는 전반적으 로 유추에 성공함을 보고하였다(Park \& Casasola, 2017).

그러나 유아기 내의 연령차를 보다 상세히 살펴보면, 4 세 이 전과 이후의 유추 능력은 분명히 차이가 나타나지만, 4 세와 5 세 사이의 유추 능력 향상에 대해서는 연구결과가 혼합되어 있 음을 알 수 있다. 예로, Goswami와 Brown (1990b)은 4, 5, 9세 아동에게 '새:새 둥지::개:?'의 형태로 구성된 유추 과제를 제시 하고 다양한 보기를 제시하였는데, '개집'을 선택한 아동은 4 세의 $59 \%, 5$ 세의 $66 \%, 9$ 세의 $94 \%$ 로 나타나 4 세와 5 세 사이에 $7 \%$ 의 증가를 보였다. 한편, 도형을 이용한 유추 문제 해결을 살펴본 Alexander 등(1989)의 연구에서는 4세와 5세의 문제 해 결에 유의한 연령차를 발견하지 못하였다. 마찬가지로, Park과 Casasola (2017)의 연구결과를 자세히 살펴보면, 구체적 사례에 서 또 다른 구체적 사례로 공간관계를 유추하는 과제에서 4세 와 5세 유아는 유추 수행에 차이를 보이지 않았고, 심지어 5세 유아의 평균 유추 점수가 4세 유아의 평균 유추 점수보다 다소 낮았다. 반면, 도형만으로 제시된 공간관계를 구체적 사례로 유추적 전이하는 과제에서는 4 세보다 5 세의 수행이 유의하게 높았다. 이러한 혼합된 결과는 4 세와 5 세 사이의 유추 수행능 력의 향상 여부에 대한 추가 연구의 필요성을 제기하며, 연령 차가 나타나거나 나타나지 않는 연구결과를 주어진 유추 과제 의 특성과 함께 고려하여 이해할 필요성을 제기한다. 
유추 과정에 관한 이론에 기초해 볼 때, 유아의 유추 수행은 유추의 대상인 관계의 특성에 의해 영향을 받을 가능성이 있 다. Sternberg와 Gardner (1983), 그리고 Pellegrino (1985)에 따 르면, 유추적 전이의 실패는 기존의 문제 상황과 새로운 문제 상황이 유사함을 깨닫는 것의 실패, 또는 유관한 지식원을 인 출해 내는 것의 실패, 즉 관련 지식이 비활성화된 상태로 남아 있는 것이 원인이 되어 일어난다. 즉, 유아가 작업기억, 실행기 능 등 인지 능력과, 유추 대상인 관계에 대한 사전 지식을 갖고 있다 하더라도, 과제와 유관한 관계적 정보에 주의가 할당되 어 인출되지 않는다면 유추에 실패할 수 있는 것이다.

실제로, 인간의 정보처리 과정에서 관계들이 주의를 받는 정도가 다름을 보여주는 연구들이 있다(Maintenant, Blaye, \& Paour, 2011; Savic, Thierry, \& Kovic, 2020; Scheuner, Bonthoux, Cannard, \& Blaye, 2004). 예를 들면, 물체를 주제적 또는 분류 학적으로 짝지을 수 있는 과제(object matching task)에서 성인 에게 물체 간의 주제적 관계(예: 소-우유)는 분류학적 관계(예: 소-당나귀)보다 더 현저한 것으로 나타났다(Savic et al., 2020). 범주화의 유연성에 관한 연구에서 주제적 범주화에서 분류학 적 범주화로의 전환이 그 반대 방향의 전환보다 어렵게 일어 나는 연구결과 또한 이러한 주제적 관계의 상대적 현저함과 관련되어 논의된 바 있다(Maintenant et al., 2011). 여기서 현 저함(salience)이란 어떤 사물이 다른 사물과 구별됨으로 인해 물리적으로 그리고 상향식으로 재인되기 쉬운 특성(physical, bottom-up distinctiveness)을 뜻한다(Fecteau \& Munoz, 2006). 또한, 한 장면(시각적 이미지)의 사물 또는 개념이 다른 사물 또는 개념과 구별되게 인식되고 즉각적인 각성을 조성하는 것 (Kadir \& Brady, 2001), 우세하게 지각되고 가장 강한 선택적 신경 반응을 초래하는 특성(van Rullen, 2003)을 의미한다.

이처럼 현저함의 정도 차이는 유추의 대상인 관계에 적용 이 가능하다. 특히, 관계들 간에 주의를 끄는 정도가 다름에 관 해 활발한 논의가 진행되어 온 영역으로 공간관계 영역이 있 다. 잘 알려진 예로, 한국어 사용자는 영어 사용자에 비해 사 물과 사물 간의 꼭 끼이는 관계(tight-fit)를 더 현저하게 지각 한다(Choi \& Hattrup, 2012). 또, 한 사물이 다른 사물의 안에 들어있는 포함관계(in)와 한 사물이 다른 사물을 바로 아래 서 떠받치고 있는 지지관계(on)는 여러 언어권에서 공통적으 로 초기에 습득되는 공간 어휘이며(Bremner \& Idowu, 1987; Clark, 1973; Johnston \& Slobin, 1979; Meints, Plunkett, Harris, \& Dimmock, 2002; Tomasello, 1987) 영아기부터 범주적 표 상을 형성하는 공간관계(Casasola \& Cohen, 2002; Casasola, Cohen, \& Chiarello, 2003; Park \& Casasola, 2015)라는 공통점
이 있지만, 이와 동시에, 여러 연구에서 포함관계가 지지관계 에 비해 영유아에게 지각되기 쉬운 것으로 나타난 바 있다. 구 체적으로, 포함관계에 대한 범주를 형성하는 능력은 지지관 계에 비해 더 이른 시기인 생후 6개월경 나타난다(Casasola \& Cohen, 2002; Casasola, et al., 2003). 또한, 소수의 예외를 제외 하고(Chang-Song, 2004), 포함관계를 표현하는 단어(in, 안) 는 지지관계를 표현하는 단어(on, 위)보다 유아에 의해 더 일 찍 이해되고 더 빈번하게 산출된다(Bowerman, 1996; Brown, 1973; Clark, 1973; Furrow, Murray, \& Furrow, 1986; Gentner \& Bowerman, 2009; Halpern, Corrigan, \& Avizer, 1983; Johnston \& Slobin, 1979; Park, 2015). 뿐만 아니라, 공간관계를 직접 구 성하는 행동에서도 걸음마기 아동은 지지관계보다 포함관계 를 더 많이 산출한다(Casasola, Bhagwat, Doan, \& Love, 2017; Corrigan, Halpern, Aviezer, \& Goldblatt, 1981). 공간관계 유추 과제에서 전반적으로 실패를 보인 3세 유아도 유일하게 유추 에 성공한 경우는 포함관계가 실제적인 구체물로 제시된 경우 였다(Park, 2015). 이처럼 포함관계에 비해 지지관계가 낮은 현 저성을 가지는 원인에 대해 Mandler (2005)는 지지관계가 도 처에 있어서 간과되는 것인지, 혹은 지지관계 개념이 중력과 무게라는, 공간적 분석을 통해서는 볼 수 없는 요인들을 포함 하기 때문인지의 의문을 제기하기도 하였다. 이를 종합해 볼 때, 포함관계와 지지관계는 유추의 대상이 되는 관계가 쉽게 파악 또는 인출되는 특성이 유아의 유추 수행에 영향을 미치 는지 살펴보기에 적합한 도구가 될 수 있다.

한편, 유추 과제에 사용되는 제시물의 유형에 의해 유아의 유추과제 수행이 어떠한 영향을 받는지 살펴본 연구들이 있 다. 유아 대상 유추 과제에서 관계는 언어적으로 제시되는 경 우도 있지만, 그보다는 사물(그림)을 통해 제시되는 경우가 많 다. 이때 제시되는 사물 자극으로는 원, 삼각형, 사각형과 같 은 도형이 사용되기도 하고, 책상, 컵과 같이 일상생활에서 접 할 수 있는 구체물이 사용되기도 한다. 도형과 구체물의 사용 이 유아의 유추에 미치는 영향을 살펴본 선행연구들은 상이한 연구결과를 발견했다. 어떤 연구들은 현실에서 사용되는 구체 물보다 도형을 사용해 관계를 제시할 때 유아의 유추 수행이 더 높다는 것을 발견하였다(Kaminski \& Sloutsky, 2010; Park \& Casasola, 2017; Son, Smith, \& Goldstone, 2011). 예로, 유아들은 $\mathrm{ABA}$ 또는 $\mathrm{BAA}$ 의 관계를 개구리와 튤립으로 제시한 경우보다 색깔이 다른 사각형으로 제시한 경우에 더 잘 유추하였다(Son et al., 2011). 또한, 크기가 점진적으로 증가하거나 감소하는 관 계에서 물체의 상대적 크기를 유추하는 과제에서도 물고기, 개 그림으로 제시한 경우보다 도형으로 제시한 경우 유추가 
촉진되었다(Kaminski \& Sloutsky, 2010). 마지막으로, 4-5세 유 아가 동일한 유형의 제시물(예: 도형-도형) 간 공간관계를 유 추하는 능력과 상이한 유형의 제시물(예: 도형-구체물) 간 공 간관계를 유추하는 능력을 살펴본 선행연구에서도 제시물 유 형이 동일한지 상이한지에 상관없이 전반적으로 기초 사례가 도형으로 공간관계를 제시한 경우 유추 수행이 높음을 발견했 다(Park \& Casasola, 2017).

그러나 이와 반대로 구체물이 유추적 전이를 촉진함을 발 견한 연구도 있다. 국내에서 $\operatorname{Kim}$ (2006)은 4-5세 유아를 대상 으로 모양, 색, 크기가 다른 블록으로 A:B::C:D 형식의 유추 과 제를 실시하였다. 과제에 사용된 블록은 도형(정사각형, 직사 각형, 원, 삼각형) 블록과 동물(다람쥐, 닭, 토끼, 곰) 블록 두 가 지였는데, 유아들은 도형 블록보다 동물 블록으로 제시된 과 제에서 더 높은 유추 수행을 보였다(Kim, 2006). 또한, 공간관 계 유추를 살펴본 연구에서 3 세 유아가 유일하게 유추에 성공 한 경우는, 포함관계가 기초 사례와 보기의 사례에서 모두 구 체물로 제시된 경우였다(Park, 2015).

이와 같은 상반된 연구결과를 설명할 수 있는 한 가지 가능 성은 유추 대상인 관계의 현저한 정도가 제시물의 유형과 상 호작용하여 유추에 영향을 미칠 가능성이다. 앞서 살펴보았듯 이, 유추를 위해서는 기초 사례에서 사물 간의 관계를 인출하 는 것이 필요하고, 관계적 구조가 현저한 정도에 있어서는 관 계들 간에 차이가 있다. 유추 과제와 관련 있는 관계가 인출되 기 어려운 관계인 경우에는 유추 과제와 관련 없는 다양한 정 보가 인출될 수 있다. 가령, 강아지 두 마리 사이에 뼈다귀가 있 는 그림자극을 제시받았을 때 참가자는 $\mathrm{ABA}$ 라는 대칭 관계와 관련 없는 정보인 “강아지들은 뼈다귀를 좋아한다.", "강아지 들이 뼈다귀를 사이에 두고 다툰다."와 같은 관계적 정보를 떠 올릴 수 있고 그 결과 유추에 혼란을 겪거나 실패할 가능성이 높아질 수 있다. 이에 비해, 두 개의 파란색 네모 사이에 노란색 네모가 있는 그림자극을 제시하는 경우 $\mathrm{ABA}$ 대칭 관계와 관 련 없는 정보가 풍부하게 산출될 가능성은 적을 수 있다. 즉, 도 형은 유추 과제와 관련 없는 정보의 양을 적게 전달함으로써, 상대적으로 인출이 어려운 관계의 유추 과제에서 유추 수행을 높일 수 있다. 이 때문에 $\mathrm{ABA}, \mathrm{BAA}$ 관계를 유추하는 선행연구 (Son et al., 2011)에서 유아들은 구체물보다 도형에서 더 좋은 수행을 보였을 수 있다. 반면에, Kim (2006)의 연구에서 '작은 다람쥐 블록: 큰 다람쥐 블록::작은 토끼 블록: ?'와 같이 구체물 로 제시되었음에도 유추 수행이 더 높게 나타날 수 있었던 것 은 '작은 것과 큰 것'이라는 관계가 유아에게 상대적으로 인출 하기 쉬운 관계였기 때문일 수 있다. 즉, 현저함이 높아 인출이
쉬운 관계와, 현저함이 낮아 인출이 상대적으로 어려운 관계의 유추 수행 차이는 관계가 도형으로 제시될 때보다 구체물로 제 시될 때 뚜렷하게 나타날 수 있다. 본 연구는 이러한 가능성을 공간관계 유추에서 확인해 보고자 한다. 구체적으로, 포함관계 와 지지관계를 유추하는 능력의 차이가 제시물이 도형일 때보 다 구체물일 때 더 두드러지는지 살펴보고자 한다.

나아가 이러한 상호작용이 유아의 연령에 따라 다르게 나 타나는지도 살펴보고자 한다. 5 세 유아는 4 세 유아에 비해 세 상에 관해 더 많은 지식을 가지고 있으므로, 구체물로 이루어 진 사례를 제시받았을 때 4 세 유아에 비해 더 풍부한 의미론 적 정보를 인출할 수 있다. 즉, 5 세 유아는 구체물 사례로부터 인출 가능한 잠재적인 관계적 정보가 4 세 유아보다 더 풍부할 수 있다. 상대적으로 현저함이 낮은 관계의 유추를 요하는 과 제에서, 이는 5세 유아의 유추 수행을 더욱 어렵게 할 수 있다. 따라서 이러한 논리에 의하면, 현저함이 낮은 관계(예: 지지관 계)를 구체물로 제시한 유추 과제에서 5 세 유아는 4 세 유아보 다 과제와 무관한 정보를 더 많이 인출하고, 그 결과 더 낮은 유추 수행을 보일 수 있다. 즉, 유아의 공간관계 유추에서 지지 관계에 대한 포함관계의 상대적 이점이 제시물이 도형인 경우 보다 구체물인 경우에 더 두드러지는 경향이 4세보다 5세 유 아에게서 더 뚜렷하게 나타날 수 있다. 아직 이러한 가능성을 살펴본 연구는 거의 없는 실정이므로, 본 연구에서 이러한 가 능성을 탐색해보고자 한다.

본 연구는 유아의 공간관계 유추가 연령, 공간관계, 제시물 의 유형에 따라 차이를 보이는지 살펴본 Park (2015), Park과 Casasola (2017)의 연구를 국내의 다른 지역에서 표집된 표본 으로 부분적으로 재확인(replication)하는 측면이 있다. 구체적 으로, 보다 다양한 공간관계의 유추적 전이를 살펴보았던 선 행연구와 달리, 본 연구에서는 관계의 현저한 정도에 따른 유 추 차이를 살펴보기 위해 지지관계와 포함관계의 유추에만 초 점을 맞추었다. 한편, 선행연구에서 도형과 구체물이 유아의 공간관계 유추 수행에 미치는 영향을 비교하기 위해 사용한 도형은 흑백의 선 그림(line drawings)으로 그려진 도형으로, 이 러한 제시물은 구체물에 비해 전달하는 의미론적 정보의 측면 에서 단순할 뿐만 아니라 지각적으로도 단순하다는 특징이 있 었다. 그 결과, 구체물은 도형에 비해 의미 면에서 풍부한 정 보를 전달할 뿐만 아니라 지각적으로도 도형에 비해 더 세밀 하고 복잡하였다. 이는 도형과 구체물 조건에서 나타난 유추 수행의 차이가 지각적 단순성에 의한 효과인지, 혹은 전달하 는 의미론적 정보의 복잡함(혹은 단순함) 때문인지를 파악하 기 어렵게 하는 제한점을 가진다. 따라서 본 연구에서는 도형 
역시 지각적으로 복잡하게 제작하여 유추 수행의 차이가 지각 적 복잡성에 의해 설명될 가능성을 줄이고자 하였다. 마지막 으로, 현실에서 유추는 이미 학습한 것을 새로운 구체적 사례 에 적용하는 경우가 대부분이기 때문에, 유추의 기초 사례와 보기의 제시물 유형을 모두 조작한 선행연구와 달리, 본 연구 에서는 유추 과제에서 보기의 제시물 유형은 구체물로 고정하 고, 기초 사례의 제시물 유형만을 조작하였다.

요약하면, 본 연구는 연령, 공간관계(포함관계, 지지관계), 제시물 유형(도형, 구체물)에 따른 유아의 유추과제 수행을 살 펴봄으로써, 다음과 같은 연구목적을 달성하고자 하였다. 먼 저, 4 세와 5세 유아가 도형 또는 구체물로 제시된 포함관계와 지지관계를 성공적으로 유추하는지 알아보고자 하였다. 다 음으로, 유아의 공간관계 유추과제 수행이 연령(4세, 5세), 공 간관계(포함관계, 지지관계), 제시물 유형(도형, 구체물)에 따 라 유의한 차이가 있는지 알아보고자 하였다. 보다 구체적으 로, 공간관계 유추 능력이 4세와 5세 사이에 향상되는지, 유아 의 공간관계 유추에서 포함관계가 지지관계보다 이점을 가지 는지를 확인하고, 유아의 공간관계 유추에서 지지관계에 대 한 포함관계의 상대적 이점이 제시물이 도형인 경우보다 구체 물인 경우에 더 두드러지는지를 확인하고자 하였다. 마지막으 로, 그러한 상호작용 효과가 4세보다 5세에서 더 뚜렷하게 나 타나는지를 확인하고자 하였다. 본 연구에서 설정한 연구문제 는 다음과 같다.

\section{연구문제 1}

4세, 5세 유아는 도형 또는 구체물로 제시된 포함관계와 지지 관계를 성공적으로 유추하는가?

\section{연구문제 2}

유아의 공간관계 유추과제 수행은 연령(4세, 5세), 공간관계 (포함관계, 지지관계), 제시물 유형(도형, 구체물)에 따라 유 의한 차이가 있는가?

\section{Methods}

\section{연구대상}

본 연구의 참여자는 만4-5세 유아 73명으로, 만4세 유아 33명 (월령 범위 48-58개월, $M=52.88, S D=2.96$, 남아 17 명, 여아 16 명)과 만5세 유아 40명(월령 범위 60-71개월, $M=66.18, S D$
$=3.17$, 남아 18 명, 여아 22 명)으로 구성되었다. 이들은 B광역 시에 소재한 어린이집과 유치원을 통해 모집되었다.

\section{연구도구}

\section{공간관계 유추 과제}

유아의 공간관계 유추를 측정하기 위해 Huttenlocher와 Levine (1990)이 개발한 The Primary Test of Cognitive Skills (PTCS)의 유추(analogies) 테스트를 Park (2015)이 수정 · 보완한 공간유 추과제(spatial analogies test)를 추가로 수정하여 사용하였다. 먼저, PTCS는 만5세 유아부터 초등학교 2학년 아동을 위한 인지 기술 평가 도구로, 연속(sequences), 유추(analogies), 기억 (memory), 언어적 추리(verbal reasoning) 테스트로 구성되어 있 는 표준화된 테스트이다. 그중에서 유추 테스트는 사람 또는 사물이 특정 관계(예: 대칭관계, 상하관계 등)에 놓여있는 모 습을 그림으로 제시하고, 그 아래에 네 개의 보기 그림을 제 시하여, 보기 중 앞에서 본 그림과 가장 비슷한(goes best with) 것을 하나 고르도록 하는 과제이다. 유아들을 대상으로 지지 관계와 포함관계의 유추 능력을 측정할 수 있는 표준화된 테 스트가 없는 상황에서 Park (2015)은 PTCS의 공간유추 테스 트 항목을 다음과 같이 수정 - 보완하였다. 첫째, 기초 사례 (sample)에 제시되는 관계를 지지관계, 포함관계, 상하관계로 하고, 보기로 제시되는 관계를 지지관계, 포함관계, 상하관계, 좌우관계로 하였다. 둘째, 유아의 인지적 부담을 줄이기 위해 보기의 개수를 네 개에서 세 개로 감소시켰다. 셋째, 제시물의 유형이 공간관계 유추에 미치는 영향을 알아보기 위해 예시 가 도형으로 구성된 과제와 구체물로 구성된 과제, 두 종류의 과제를 제작하였다. 이때, 구체물 자극은 별도의 예비조사에 서 유아에게 친숙한 사물 선정, 선정된 사물간에 실제 일어나 는 공간관계, 이에 대한 언어적 묘사를 거쳐 결정되었다(Park, 2015). 본 연구는 이러한 공간유추과제에서 포함관계와 지 지관계 유추를 테스트하는 항목만 사용하고, 선행연구(Park, 2015; Park \& Casasola, 2017)의 도형 자극이 지녔던 단점, 즉 구 체물에 비해 지각적으로도 단순한 특성을 가지고 있어 의미론 적 단순성에 의한 효과만을 살펴보기 어려웠다는 점을 보완하 기 위해 MS Power Point로 무늬와 색을 추가한 도형을 사용하 였다. 예시가 구체물로 구성된 과제는 선행연구의 구체물 과 제를 그대로 사용하였다. Figure 1은 도형 과제와 구체물 과제 에 있는 지지관계 유추 문항과 포함관계 유추 문항의 예를 보 여준다. 


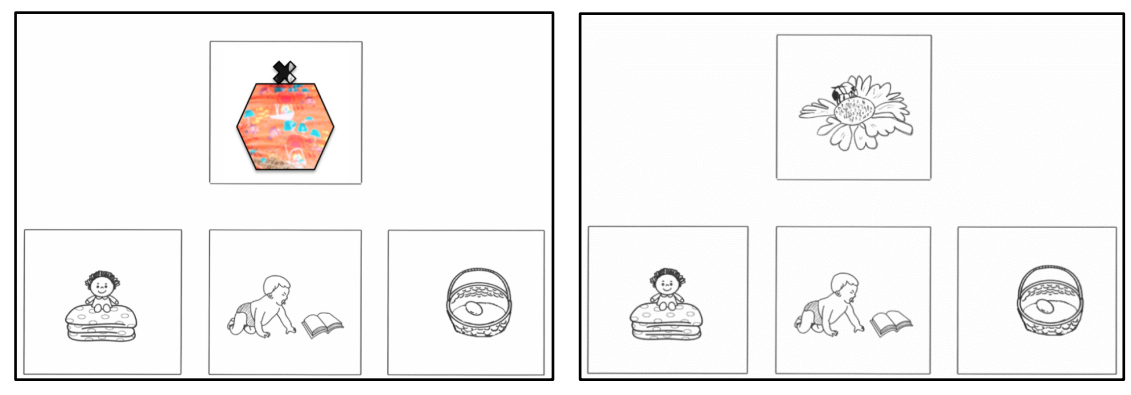

\section{Support (ON)}

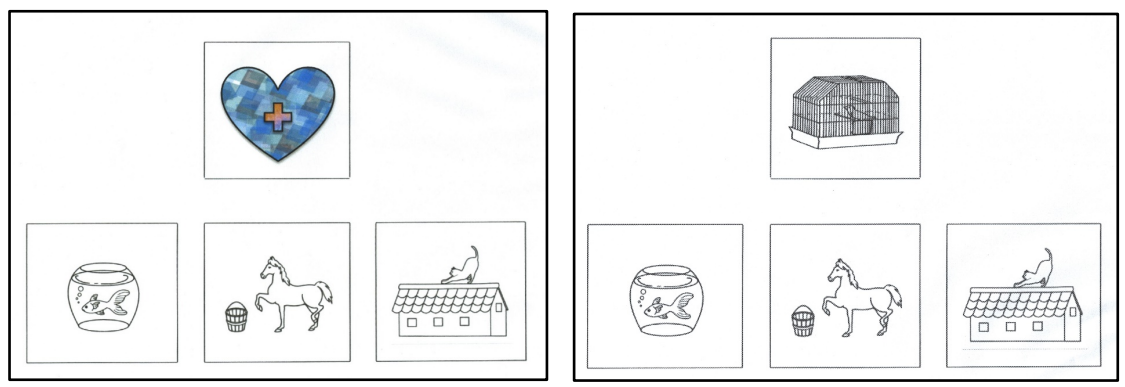

Containment (IN)

Figure 1. Sample spatial analogy items for support and containment relations.

공간관계 유추 과제는 지지관계 유추 4 문항, 포함관계 유추 4문항으로 구성되어 있었다. 각 문항 상단에 지지관계 또는 포 함관계를 보여주는 예시가 제시되었고, 각 문항 하단에 세 개 의 보기가 제시되었다. 예시는 과제 조건에 따라 도형 또는 구 체물로 구성되었고, 보기는 항상 구체물로 구성되었다. 보기 중 하나는 예시에 나타난 공간관계의 사례였고, 나머지 두 개 의 보기는 예시에 나타나지 않은 공간관계의 사례였다. 보기 중에서 예시와 같은 공간관계의 사례인 보기의 위치는 각 문 항 내에서 무선으로 결정되었다. 8 문항에 대한 제시순서는 세 가지 순서가 사용되었다.

\section{연구절차}

자료 수집은 연구에 대한 설명문을 읽고 보호자가 자녀의 연 구 참여에 대한 서면 동의를 제공한 유아들을 대상으로 이루 어졌다. 한 명의 연구원이 모든 유아에 대한 자료를 수집하였 으며, 유아가 다니는 어린이집, 유치원 내의 조용한 공간에서 일대일 면접 형식으로 이루어졌다. 연구원은 공간관계 유추 과제를 제시하기 전에 유아와 약 1-2분간 짧은 대화를 나누며 라포를 형성하고 나서, "선생님이 $\mathrm{OO}($ 이)에게 보여주려고 퀴 즈를 가지고 왔어요."하며 과제를 소개하였다. 이어서 “선생 님이 $\mathrm{OO}($ 이)에게 그림을 보여줄 거예요. 그럼 $\mathrm{OO}($ 이)는 그림 을 잘 보고 선생님이 물어보는 말에 대답해주면 돼요. 알겠지
요?”라고 설명하였다. 유아가 고개를 끄덕이거나 대답을 하면 연구원은 유아를 도형 조건과 구체물 조건 중 하나에, 그리고 문항을 제시하는 세 가지 순서 중 하나에 무선 할당하였다(예: 도형 조건 + 제시순서 1$)$.

유아를 제시물 유형 조건과 제시순서에 할당하고 난 후, 공 간관계 유추 과제를 시작하였다. 첫 번째 문항에서 연구원은 “자, 이 그림을 보세요.”라고 하며 유아에게 예시 자극을 제시 하였다. 3 초 후 연구원은 “그리고 나서 이 그림들을 보세요." 라고 하며 하단의 보기 세 개를 보여주었다. 다시 3 초 후 연구 원은 "(보기들을 손으로 가리키며) 여기 있는 이 그림들 중에 서 어떤 것이 여기(예시를 손으로 가리키며) 있는 그림과 가 장 잘 맞는 짝꿍 그림일까요?”하고 질문하였다. 이러한 질문 은 원 과제에서 사용된 질문 "Which one of these pictures goes best with this picture?”를 최대한 우리말로 가깝게 번역하면서 유아가 이해하기 쉽도록 한 것이었다. 구체적으로, 'goes best with'를 우리말로 가장 가깝게 번역한 표현으로 '잘 어울리는' 것이 있으나, 우리나라 유아에게 '잘 어울리는 것'을 고르도 록 했을 때 '옆에(혹은 함께) 두기에 적당하거나 보기 좋은 것 (look good)'으로 해석될 수 있다는 유아교사의 의견이 있었다. 또한, 유아 수학 교재들에서 '짝 찾기', '짝꿍 찾아주기'라는 표 현이 빈번히 사용됨을 근거로 '짝꿍'이라는 표현을 사용하였 다. 수정된 표현은 한국어-영어 이중 언어 사용자인 유아교사 의 역번역을 거쳐 결정되었다. 예시와 보기를 짝짓는 다양한 
과제들(matching tasks)에서 다소 다른 지시문들이 사용되었 는데, 예를 들면, 'goes best (Waxman \& Namy, 1997)', 'goes with (Waxman \& Namy, 1997)'외에도 'the most like (Deak \& Bauer, 1995)', 'the same kind of thing (Deak \& Bauer, 1995)' 등이 사용 되었다. 선행연구에 따르면, 우리말로 '가장 비슷한'에 해당하 는 'the most like'라는 표현을 지시문에 사용하는 경우 유아들 의 표면적 유사성에 근거한 선택을 촉진하는 경향이 있고, 우 리말로 '같은 종류의 것'에 해당하는 'the same kind of thing'이 라는 표현을 지시문에 사용하는 경우 분류학적 범주에 근거한 선택을 촉진하는 경향이 있었다(Deak \& Bauer, 1995). 이에 비 해, 'goes best with'는 모호한 표현으로 주제적 관계(예: 원숭이바나나)를 포함한 보다 다양한 근거에 의한 선택을 촉진하는 경향이 있었다(Waxman \& Namy, 1997). 따라서 본 연구에서 도 ‘비슷한 것', '같은 종류’라는 표현을 피하고자 하였다.

유아가 보기 중 하나를 손으로 가리켜 응답하면 연구원은 유아의 선택을 조사지에 기록하고 다음 문항으로 넘어갔다. 이 러한 과정이 1 번 문항부터 8 번 문항까지 반복되었다. 유아의 과제 수행 과정은 비디오로 녹화되었으며, 모든 문항이 끝난 뒤 유아는 스티커 세트를 선물로 받았다. 유아의 응답은 유아 가 예시와 같은 공간관계를 나타내는 보기를 고른 경우(1점), 그 외의 보기를 고른 경우(0점)로 코딩되었다. 이렇게 코딩된 점수를 합하여 공간관계 유형별 유추 점수와 공간관계 유추 총점을 산출하였다. 가능한 점수 범위는 공간관계 유형별 유추 점수의 경우 0-4점, 총점의 경우 0-8점이었다.

\section{자료분석}

수집된 자료는 SPSS 21.0 프로그램(IBM Co., Armonk, NY)을 사용하여 분석하였다. 먼저, 유아의 공간관계 유추 성공 여부 를 알기 위해 유아의 평균점수를 우연수준과 비교하는 단일표 본 $t$ 검증을 실시하였다. 유아의 유추가 연령(4세, 5 세), 공간 관계(포함, 지지), 제시물의 유형(도형, 구체물)에 따라 차이가 있는지 알아보기 위해 연령과 제시물 유형을 피험자 간 변인 으로, 공간관계를 피험자 내 변인으로 하는 $2 \times 2 \times 2$ 혼합설계 분산분석(mixed-design ANOVA)을 실시하였다. 유의하게 나타 난 상호작용 해석을 위해서는 대응표본 $t$ 검증을 사용하였다.

\section{Results}

\section{연령, 공간관계, 제시물 유형에 따른 유아의 유추 성공 여부}

Table 1은 유아의 연령, 공간관계, 제시물 유형에 따른 유추 점 수의 평균과 표준편차를 보여준다. 유추 성공 여부를 알아보기 위해, 유아의 유추 점수를 유아가 과제에 임의로 응답하는 경우 기대되는 점수인 우연 수준과 비교한 결과는 다음과 같았다.

4 세 유아 중 도형 조건의 유아들은 포함관계 $(t(16)<1$, n.s. $)$ 와 지지관계 $(t(16)<1, n . s$.$) 의 유추 점수 모두 우연 수준과 유$

Table 1

Means and Standard Deviations of Spatial Analogy Scores by Age, Relation, and Object Type

\begin{tabular}{|c|c|c|c|c|}
\hline & & Containment & Support & Total \\
\hline \multicolumn{5}{|l|}{ 4-year-olds } \\
\hline & Geometric shapes & $1.29(0.77)$ & $1.53(1.13)$ & $2.82(1.29)$ \\
\hline & Total & $1.73(0.98)^{*}$ & $1.39(1.12)$ & $3.12(1.54)^{+}$ \\
\hline \multicolumn{5}{|l|}{ 5-year-olds } \\
\hline & Concrete objects & $2.05(1.36)^{*}$ & $1.70(0.80)^{+}$ & $3.75(1.74)^{*}$ \\
\hline & Total & $2.05(1.22)^{* * *}$ & $1.98(1.07)^{* * *}$ & $4.03(1.82)^{* * *}$ \\
\hline \multicolumn{5}{|l|}{ Total } \\
\hline & Geometric shapes & $1.70(1.02)^{*}$ & $1.92(1.23)^{* *}$ & $3.62(1.78)^{* *}$ \\
\hline
\end{tabular}

Note. A cross mark represents a significantly different score compared to the chance level at $\alpha=.10$. ${ }^{*} p<.05 .{ }^{* *} p<.01 .{ }^{* * *} p<.001$. 


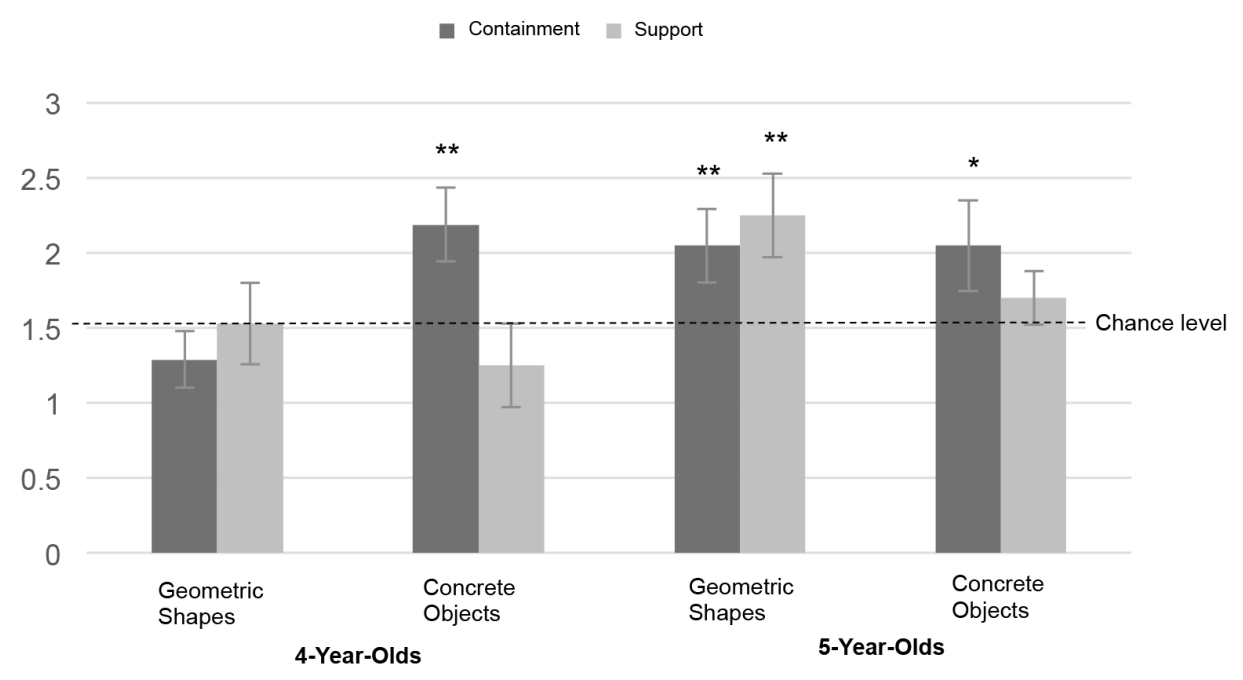

Figure 2. Mean scores on spatial analogies test by age, relation, and object type. Error bars refer to $\pm 1 S E$ (standard error).

${ }^{*} p<.05 .{ }^{* *} p<.01 .{ }^{* * *} p<.001$.

의한 차이가 없었다. 한편, 4 세 유아 중 구체물 조건의 유아 들은 포함관계 유추 점수는 우연 수준보다 유의하게 높았고 $(t(15)=3.48, p=.003)$, 지지관계 유추 점수는 우연 수준과 유 의한 차이가 없었다 $\left(t(15)<1, n . s_{\text {. }}\right)$. 즉, 4 세 유아는 구체물로 제시된 포함관계만 성공적으로 유추하였다.

다음으로, 5 세 유아 중 도형 조건의 유아들은 포함관계 $(t(19)=2.92, p=.009)$ 와 지지관계 $(t(19)=3.28, p=.004)$ 의 유추 점수 모두 우연 수준보다 높았다. 한편, 5세 유아 중 구체 물 조건의 유아들은 포함관계 유추 점수는 우연 수준보다 유 의하게 높았고 $(t(19)=2.36, p=.029)$, 지지관계 유추 점수는 우연 수준과 유의한 차이가 없었다 $(t(19)=2.05, p=.055)$. 즉, 5 세 유아는 두 가지 제시물 유형 모두에서 포함관계 유추에 성 공하였고, 지지관계 유추는 지지관계가 도형으로 제시된 경우 에만 성공하였다.

4세와 5세의 유추 성공 여부 결과를 종합하면, 두 연령 집단 모두 지지관계 유추보다 포함관계 유추에 더 쉽게 성공함을 알 수 있다. 또한, 5 세 유아도 구체물로 제시된 지지관계 유추 를 수행하는 것이 쉽지 않음을 보여준다.

\section{연령, 공간관계, 제시물 유형에 따른 유아의 유추과제 수행 차이}

유아의 연령, 공간관계, 제시물 유형이 유아의 공간관계 유추 에 어떠한 영향을 미치는지, 본 연구의 독립변인들의 주효과 와 상호작용 효과를 알아보기 위해 혼합설계 분산분석을 실시
한 결과는 다음과 같았다. 연령의 주효과 $(F(1,69)=5.03, p<$ .05)와 공간관계 $\times$ 제시물 유형의 이원상호작용 효과 $(F(1,69)$ $=7.24, p<.01)$ 가 유의하게 나타났다. 그 외에 유의한 주효과 또는 상호작용 효과는 없었다.

먼저 연령의 주효과를 살펴보면, 공간관계와 제시물 유형 을 통틀어, 전반적으로 5세 유아의 유추 점수 $(M=2.01, S E=$ $0.13)$ 가 4 세 유아의 유추 점수 $(M=1.57, S E=0.15)$ 보다 유의 하게 높았다 $(p<.05)$. 연령과 다른 변인들 간의 유의한 상호작 용이 나타나지 않았으므로, 이는 공간관계를 유추하는 전반적 인 능력이 4세와 5 세 사이에 유의하게 향상됨을 보여준다.

다음으로, 공간관계와 제시물 유형 간의 이원상호작용을 구체적으로 이해하기 위해 제시물 유형별로 지지관계와 포함 관계 유추 점수를 비교하는 대응표본 $t$ 검증을 실시하였다. 즉, 제시물 유형별로 공간관계에 따른 유추과제 수행 차이를 살펴 보았다. 그 결과, Figure 2에서 볼 수 있는 바와 같이, 도형 조건 에서는 포함관계와 지지관계의 유추 점수 간에 유의한 차이가 없었고 $(t(36)<1, n . s$.$) , 구체물 조건에서는 포함관계 유추 점$ 수가 지지관계 유추 점수보다 유의하게 높았다 $(t(35)=2.79, p$ $=.009)$. 즉, 포함관계와 지지관계의 유추 수행 차이는 공간관 계가 구체물로 제시된 조건에서만 나타났다.

\section{Discussion}

본 연구는 연령, 공간관계, 제시물 유형에 따른 유아의 유추과 
제 수행을 살펴보았다. 먼저, 4세와 5세 유아가 도형 또는 구체 물로 제시된 포함관계와 지지관계를 성공적으로 유추하는지 알아보고자 하였다. 다음으로, 유아의 공간관계 유추과제 수 행이 연령(4세, 5 세), 공간관계(포함관계, 지지관계), 제시물 유 형(도형, 구체물)에 따라 유의한 차이가 있는지 알아보고자 하 였다. 보다 구체적으로, 공간관계 유추 능력이 4세와 5세 사이 에 향상되는지, 유아의 공간관계 유추에서 포함관계가 지지관 계보다 이점을 가지는지를 확인하고, 유아의 공간관계 유추에 서 지지관계에 대한 포함관계의 상대적 이점이 제시물이 도형 인 경우보다 구체물인 경우에 더 두드러지는지를 확인하고자 하였다. 마지막으로, 그러한 상호작용 효과가 4세보다 5세에서 더 뚜렷하게 나타나는지를 확인하고자 하였다. 본 연구의 결과 를 정리하고 선행연구와의 관련성을 논의하면 다음과 같다.

첫째, 유아의 유추과제 수행을 우연 수준과 비교한 결과, 4 세 유아는 구체물 조건에서 포함관계를 유추할 수 있었던 반 면 지지관계는 유추하지 못했다. 이는 영유아가 구체물로 제 시된 지지관계를 파악하고 습득하는 데 어려움을 보인다는 선행연구 결과들로 설명될 수 있다(Casasola \& Cohen, 2002; Gentner \& Bowerman, 2009; Park, 2015). 대표적으로, 자동차 장난감, 동물 인형 등 일상생활에서 사용되는 사물로 포함관 계와 지지관계의 사례들을 제시했을 때, 생후 10 개월 영아 는 포함관계의 범주적 표상을 형성하는 데 성공하고 지지관 계의 범주적 표상을 형성하는 데 실패했다(Casasola \& Cohen, 2002). 또한, 3 세 유아는 구체물로 제시된 포함관계는 유추에 성공하고 지지관계는 유추에 실패하였다(Park, 2015). 본 연구 의 결과는 영유아가 구체물에서 지지관계를 파악하는 것이 포 함관계를 파악하는 것보다 더 어렵다는 선행연구 결과를 4세 유아의 유추 수행에까지 확장하며, 구체물이 4 세 유아에게 포 함관계를 전달하고 유추하게 하는 데 효과적임을 보여준다.

한편, 동일한 연령의 4세 유아가 도형 조건에서는 두 공간관 계 모두 유추에 실패했다. 이는 일상생활에서 볼 수 있는 구체 물을 통해 파악이 가능한 포함관계라 하더라도, 제시물 유형에 따라서는 파악이 어려워질 수 있음을 암시한다. 한편, 이러한 결과는 지각적으로 단순한 도형을 사용한 선행연구에서 4 세 유아가 포함관계와 지지관계를 모두 성공적으로 유추한 연구 결과와 차이가 있다(Park \& Casasola, 2017). 본 연구의 도형 자 극의 경우, 도형에 무늬와 색이 추가되어 지각적으로 복잡해진 점이 이러한 상이한 연구결과를 초래했을 수 있다. 가령, 흑백 의 선 그림으로 나타낸 도형 그림에 비해 다채로운 색상의 도형 그림을 볼 때, 유아는 제시되는 그림이 두 개의 물체로 이루어 져 있다고 인식하는 데 어려움을 겪을 수 있다. 4 세 유아의 유
추 수행을 우연 수준과 비교한 결과를 종합해 볼 때, 이는 지지 관계보다 포함관계의 유추가 먼저 가능하다는 점, 구체물에서 지지관계에 비해 포함관계가 이점을 가진다는 점, 그리고 포함 관계의 이점이 도형에서는 나타나지 않는다는 점을 보여준다.

둘째, 유아의 유추과제 수행을 우연수준과 비교한 결과, 5 세 유아는 구체물 조건에서 포함관계만 유추할 수 있었고, 도 형 조건에서는 두 공간관계 모두 유추할 수 있었다. 이러한 결과는 우선, 5 세에도 구체물로 제시된 사례에서 지지관계 를 파악하는 것이 여전히 어려움을 나타내는 것으로, 구체물 조건에서 지지관계 유추에 성공하였던 선행연구 결과(Park \& Casasola, 2017)와는 상이하다. 그러나 선행연구(Park \& Casasola, 2017)에서도 5세 유아가 구체물 자극조건에서 지지 관계를 유추하는 점수는 포함관계 유추 점수나, 도형 자극조 건에서 지지관계를 유추하는 점수에 비해 낮았다는 점, 본 연 구의 유추 점수는 선행연구(Park \& Casasola, 2017)의 유추 점 수보다 전반적으로 다소 낮게 나타난 경향이 있었다는 점을 고려하면, 본 연구에서 나타난 5세 유아의 유추 수행 점수의 패턴은 선행연구와 일치하였다고 할 수 있다.

또한, 5 세 유아의 유추 성공 여부를 살펴본 결과는 5 세경 유 아가 지지관계를 성공적으로 유추하기 시작하며, 흥미롭게 도 이때 유아는 지지관계의 성공적 유추를 도형 조건에서 먼 저 보이기 시작한다는 점을 보여준다. 이는 포함관계의 성공 적 유추가 나타나기 시작하는 조건과 차이를 보이는 것으로, 인출이 어려운 관계인 경우 유추과제와 관련 없는 정보의 양 을 감소시킨 도형이 관계의 파악 및 유추를 촉진할 수 있을 것 이라는 본 연구의 가설과도 같은 맥락의 결과이다. 그 외에, 본 결과는 5세경 포함관계를 제시자극 유형과 상관없이 상당히 안정적으로 유추할 수 있다는 것을 보여주며, 구체물로 제시 된 지지관계에 대해서는 아직 안정적으로 유추하지 못한다는 점을 보여준다.

4세와 5 세의 유추 성공 여부 결과를 종합하면, 지지관계 유 추보다 포함관계 유추가 더 이른 시기에 가능해지며, 먼저 안 정적으로 가능해짐을 알 수 있다. 이러한 결과는 포함관계의 범주가 지지관계의 범주보다 더 일찍 습득되고 공간어휘 습 득에서도 '안' 또는 'in'이 '위' 또는 'on'보다 먼저 습득되는 영 아기 및 유아기 초기의 차이(Casasola \& Cohen, 2002; Casasola et al., 2003; Furrow et al., 1986; Gentner \& Bowerman, 2009; Halpern et al., 1983; Johnston \& Slobin, 1979; Park \& Casasola, 2015)가 유아기까지 확장됨을 암시한다. 영아가 공간관계의 사례로부터 추상적인 범주표상을 형성하는지를 살펴본 연구 들에서 포함관계 범주화가 지지관계보다 앞서서 출현한다. 바 
구니에 담긴 원숭이 인형 등의 구체물 사례들로부터 포함관계 의 추상적 범주표상을 형성하는 능력은 생후 6개월에 나타난 다(Casasola \& Cohen, 2002; Casasola et al., 2003). 그러나 동일 한 구체물 자극을 가지고 지지관계의 사례들을 제시하였을 때 영아는 지지관계의 추상적 범주표상을 형성하지 못한다. 동 일한 구체물로 지지관계의 범주적 표상을 형성하는 것은 생 후 18 개월에 가능했다(Casasola \& Cohen, 2002). 종합하면, 구 체물로 조성된 포함관계는 구체물로 조성된 지지관계보다 영 유아에게 더 흥미로운 특징을 가지거나 지각적으로 두드러져, 관계의 구조를 현저히 드러내도록 함으로써 더 일찍 그 개념 이 습득되는 것으로 보인다.

셋째, 공간관계 유추에 있어서 공간관계 유형, 제시자극의 특성, 연령의 효과를 파악하기 위해 실시한 분산분석의 결과, 연령의 효과가 유의하다는 사실을 확인할 수 있었다. 즉, 도형 과 구체물, 지지와 포함관계를 통틀어 살펴본 전반적인 공간관 계 유추 능력은 4 세와 5 세 사이에 향상되는 것으로 나타났다. 이는 구체물로부터 또 다른 구체물로의 공간관계 유추 수행 이 4세와 5세 사이에 향상되지 않은 선행연구(Park \& Casasola, 2017) 결과와 불일치하는 것으로 보인다. 그러나 본 연구의 결 과를 자세히 살펴보면, 이러한 유추 수행의 향상은 도형 조건 에서 뚜렷하게 나타나며, 구체물 조건에서는 큰 변화가 없고 오히려 구체물 조건에서 5세의 포함관계 유추는 4세보다도 조 금 낮은 평균 점수를 나타냈음을 알 수 있다. 따라서 이 시기에 전반적인 유추 능력의 향상이 있지만, 그러한 향상이 주로 도 형 조건에 의해 주도되었음을 고려할 필요가 있다. 한편, 이러 한 유추 능력 향상은 여러 가지 인지 능력의 성숙과 경험, 발달 적 진보가 상호작용한 결과일 가능성이 크다. 4세와 5세 사이 에 공간관계 개념과 사례에 대한 지식이 풍부해지고, 지식 자 원에서 공간관계를 인출하는 능력이 향상되며, 사례를 구성하 는 요소들을 대응시키는 능력이 향상되기 때문일 수 있다. 사 례 간의 표면적 유사성에서 관계적 정보의 유사성으로 관심이 이동하는 인지적 변화인 소위 '관계적 이동(relational shift)'을 경 험하는 것(Gentner \& Rattermann, 1991)이 영향을 줄 수도 있다. 표면적 유사성에 대한 관심을 억제하고 관계적 유사성에 초점 을 유지할 수 있도록 돕는 실행 기능 등, 유추에 한정되지 않 는 일반적인 인지 능력의 향상(Halford, 1993; Thibaut \& French, 2016)도 유아의 유추 수행 향상에 역할을 하였을 수 있다.

넷째, 본 연구의 결과는 제시물 유형에 따라 유아의 포함관 계와 지지관계 유추 수행 간 차이가 달라진다는 가설을 지지 하였다. 그러나 그러한 상호작용이 4세아보다 5세아에서 더 뚜렷할 것이라는 삼원상호작용에 대한 가설은 지지되지 못하
였다. 즉, 연령과 상관없이 유아들은 도형 자극을 제시받은 경 우에는 포함관계와 지지관계의 유추 수행에 차이가 없었고, 구체물 자극을 제시받은 경우에는 포함관계를 지지관계보다 더 용이하게 유추하였다. 지지관계 유추에 대한 포함관계 유 추의 상대적 용이성이 유추 과제에서 사용된 제시물의 유형에 따라서 나타나거나 혹은 나타나지 않는다는 본 연구의 결과는 새로운 연구결과이다. 이러한 결과는 제시자극이 도형인지 구 체물인지의 특성만이 독자적으로 유아의 유추에 영향을 미치 기보다는, 관계 구조 자체의 특성과 제시물의 유형이 상호작 용해서 유아의 유추에 영향을 미침을 보여준다. 구체물 자극 을 제시한 경우 유아가 지지관계보다 포함관계 유추과제를 더 잘 수행하였다는 것은 포함관계가 갖는 관계 구조의 현저성 에 의한 것일 수 있다. 앞서 살펴본 대로 포함관계는 지지관계 에 비해 관계 구조의 현저성이 높아 유아가 '포함'이라는 관계 를 쉽게 인출할 수 있다. 사물을 담는 용도로 사용되는 바구니, 집 등의 구체물은 관계구조를 인출하는 데 도움을 주었을 수 도 있다. 이에 비해 지지관계의 경우 관계구조의 현저성이 상 대적으로 낮기 때문에, 제시된 사물 간의 관계가 '지지' 관계라 는 사실을 인출하기가 어렵다. 이처럼 관계 구조의 인출이 어 려운 상황에서 제시된 자극이 도형이라면 사물 간의 가능한 관계를 좁혀가는 데 도움이 될 수가 있다. 이에 반해 제시된 자 극이 구체물인 경우에는 두 사물 간의 가능한 관계 경우의 수 가 훨씬 많아져 오히려 인출에 방해가 된다.

연령이 증가함에 따라 구체물에 대한 지식이 풍부해지고 관계에 대해 습득한 정보가 많아질수록 관계 구조 인출과정에 서 더 큰 혼란에 빠지게 되고, 결과적으로는 유추에 성공하기 더 어려워진다는 가설은 지지되지 않았다. 이는 4세와 5세 유 아의 유추 수행 능력이 전반적으로 향상된 것에서 알 수 있듯 이, 5 세 유아는 세상에 대한 지식이 4세 유아보다 더 많이 축 적되어 구체물 사례를 제시받았을 때 유추 과제와 무관한 정 보를 더 풍부하게 산출할 수도 있지만, 동시에 공간관계에 대 한 지식과 경험도 더 축적이 되었기에 공간관계를 파악하는 능력 역시 향상되었기 때문일 수 있다. 즉, 현저함이 낮은 관계 에 대한 경험의 축적과, 전반적인 유추 수행 능력의 향상이, 현 저함이 낮은 관계가 구체물로 표현될 때 초래되는 부정적 결 과를 보상하는 것일 수 있다.

결론적으로, 본 연구는 4 세와 5 세 사이에 유아의 공간관계 유추 능력이 전반적으로 향상되며, 특히 지지관계 유추에 비 해 포함관계 유추가 가지는 상대적 용이성은 이들 공간관계가 일상생활의 구체물로 제시될 때 두드러짐을 처음으로 보여준 다. 지지관계가 구체물이 아닌 도형으로 제시될 때 5 세 유아는 
이를 포함관계 유추만큼이나 성공적으로 유추할 수 있다. 이 는 유추를 효과적으로 촉진할 수 있는 제시물 유형이 관계의 현저성에 따라 다를 수 있음을 의미한다.

본 연구의 결과는 다음과 같은 의의와 시사점을 가진다. 우 선, 본 연구는 유추 수행 능력의 향상에 관한 연구결과가 혼합 되어 있는 4-5세 유아의 유추과제 수행에 집중함으로써 4-5세 사이 공간관계 유추의 발달적 변화 양상을 포착하였다는 데 의의가 있다. 유아가 지지관계 유추보다 포함관계 유추를 발 달의 더 이른 시점에 보인다는 발견과, 지지관계와 구체물이 조합되었을 때 유추가 어렵다는 발견은 발달의 횔씬 이른 시 기인 영아기의 공간관계 범주화에서 나타나는 변화 양상과의 유사성을 드러낸다. 또한 이 연구는 포함관계 유추만 가능한 단계에서 지지관계 유추가 가능한 단계로 변화하는 전이기에 각각의 공간관계가 자극 유형에 의해 상이한 영향을 받음을 처음으로 밝혔다는 데 중요성이 있다. 나아가, 본 연구의 결과 는 유아교육현장에서 교육활동 계획이나 교구 제작 시 유용한 경험적 근거를 제공한다. 즉, 공간관계의 특성에 따라 유추를 촉진할 수 있는 자극 유형을 찾아내어 학습을 돕고자 하는 데 사용될 수 있다. 실제로 유아기에는 다양한 관계적 개념이 습 득되고 유아교육 현장에서는 이러한 학습과정에서 관계적 개 념을 그림으로 제시하는 경우가 많다. 본 연구를 통해 자극 유 형에 따라 유아가 관계적 개념을 한 사례에서 다른 사례로 전 이하는 것의 수월성에 차이가 있음이 확인된 만큼, 교육현장 에서 개인의 유추능력을 높일 수 있는 다양한 개입방법을 마 련하는 데 기초자료가 될 것이다.

마지막으로 본 연구의 제한점을 통한 후속연구 제언을 하 고자 한다. 먼저, 4-5세 유아들을 대상으로 연구를 실시한 것 은 발달 초기의 변화를 볼 수 있게 하였지만, 그만큼 연구결과 를 전체 유아들에게 일반화시키는 데는 한계가 있다. 주변 사 물에 대한 지식이 더 증가하는 6세 유아까지 대상을 확장하였 을 때 구체물에서의 포함, 지지관계의 유추가 향상될지 아니 면 오히려 감소할지가 확인된다면 발달적 변화를 보다 더 명 확히 규명할 수 있을 것이다. 또한 공간관계를 제시하기 위해 2 차원의 그림을 사용하였는데, 3 차원의 실물 도형과 구체물 을 가지고 유아의 공간유추를 테스트하였을 때에도 연구결과 가 동일하게 확인되는지 알아보는 연구로 확장해 볼 필요가 있다. 교육현장에서 학습지 등을 통해 2차원으로 관계를 제시 하는 방법이 보편적으로 사용되기는 하지만 유아들에게는 실 물을 가지고 조작하는 것 또한 널리 사용되기 때문이다. 더 나 아가 유아가 자극을 직접 조작하게 했을 경우 유추수행이 향 상되는지와 같이 유추를 촉진할 수 있는 효과적인 방법을 찾
아 도움을 줄 필요가 있다. 또한, 본 연구에서는 유아의 지지관 계 및 포함관계에 대한 사전 지식을 통제하지 않았다. 4세와 5 세 유아들은 대부분 이미 '안'과 ‘위'라는 위치어를 습득한 상 태이지만(Park, 2015), 그럼에도 불구하고 포함관계와 지지관 계에 대한 사전 지식의 개인차를 측정하여 이를 통제한 상태 에서 독립변인의 효과를 살펴보는 연구를 수행할 필요가 있 다. 마지막으로, 본 연구에서 사용된 공간관계 유추과제는 영 어의 포함관계와 지지관계와 일치하는 사례들로 구성되어 있 다. 추후 한국 유아를 대상으로 타당도와 신뢰도를 검증한 공 간관계 유추과제의 개발이 필요하다.

\section{Acknowledgements}

This work was supported by the Ministry of Education of the Republic of Korea and the National Research Foundation of Korea (NRF-2017S1A5A8021138).

\section{Conflict of Interest}

No potential conflict of interest relevant to this article was reported.

\section{References}

\section{In English}

Alexander, P. A., Wilson, V. L., White, C. S., Fuqua, J. D., Clark, G. D., Wilson, A. F., \& Kulikowich, J. M. (1989). Development of analogical reasoning in 4- and 5-year-old children. Cognitive Development, 4(1), 65-88. doi:10.1016/08852014(89)90005-1

Bowerman, M. (1996). Learning how to structure space for language: A cross-linguistic perspective. In P. Bloom, M. A. Peterson, L. Nadel, \& M. F. Garrett (Eds.), Language and Space (pp. 385-436). Cambridge, MA: MIT Press. doi:10.7551/ mitpress/4107.003.0012

Bremner, J. G., \& Idowu, T. C. (1987). Constructing favourable conditions for measuring the young child's understanding of the terms in, on and under. International Journal of Behavioral Development, 10(1), 89-98. doi:10.1177/016502548701000106

Brown, R. (1973). A first language: The early stages. Cambridge, MA: Harvard University Press. 
Casasola, M., Bhagwat, J., Doan, S. N., \& Love, H. (2017). Getting some space: Infants and caregivers' containment and support spatial constructions during play. Journal of Experimental Child Psychology, 159, 110-128. doi:10.1016/ j.jecp.2017.01.012

Casasola, M., \& Cohen, L. B. (2002). Infant categorization of containment, support, and tight-fit spatial relationships. Developmental Science, 5(2), 247-264. doi:10.1111/14677687.00226

Casasola, M., Cohen, L. B., \& Chiarello, E. (2003). Six-monthold infants' categorization of containment spatial relations. Child Development, 74(3), 679-693. doi:10.1111/14678624.00562

Choi, S., \& Hattrup, K. (2012). Relative contribution of perception/cognition and language on spatial categorization. Cognitive Science, 36(1), 102-129. doi:10.1111/j.15516709.2011.01201.x

Clark, E. V. (1973). Non-linguistic strategies and the acquisition of word meanings. Cognition, 2(2), 161-182. doi:10.1016/00100277(72)90010-8

Corrigan, R., Halpern, E., Aviezer, O., \& Goldblatt, A. (1981). The development of three spatial concepts: In, on, under. International Journal of Behavioral Development, 4(4), 403419. doi:10.1177/016502548100400402

Deak, G., \& Bauer, P. J. (1995). The effects of task comprehension on preschoolers' and adults' categorization choices. Journal of Experimental Child Psychology, 60(3), 393-427. doi:10.1006/ jecp.1995.1047

Fecteau, J. H., \& Munoz, D. P. (2006). Salience, relevance, and firing: A priority map for target selection. TRENDS in Cognitive Science, 10(8), 382-390. doi:10.1016/j.tics.2006.06.011

Ferry, A. L., Hespos, S. J., \& Gentner, D. (2015). Prelinguistic relational concepts: Investigating analogical processing in infants. Child Development, 86(5), 1386-1405. doi:10.1111/ cdev. 12381

Furrow, D., Murray, P., \& Furrow, M. (1986). Spatial term use and its relation to language function at two developmental stages. First Language, 6(16), 41-51. doi:10.1177/014272378600601604

Gentner, D. (1983). Structure-mapping: A theoretical framework for analogy. Cognitive Science, 7, 155-170. doi:10.1207/ s15516709cog0702_3

Gentner, D. (1989). The mechanisms of analogical learning. In S. Vosniadou \& A. Ortony (Eds.), Similarity and Analogical Reasoning. Cambridge, MA: Cambridge University Press.

Gentner, D., \& Bowerman, M. (2009). Why some spatial semantic categories are harder to learn than others: The typological prevalence hypothesis. In J. Guo, E. Lieven, N. Budwig, S. Ervin-Tripp, K. Nakamura, \& Ş. Özçaliskan (Eds.), Crosslinguistic Approaches to the Psychology of Language: Research in the Tradition of Dan Isaac Slobin (pp. 465-480).
New York: Psychology Press.

Gentner, D., \& Rattermann, M. J. (1991). Language and the career of similarity. In S. A. Gelman \& J. P. Brynes (Eds.), Perspectives on Language and Thought: Interrelations in Development (pp. 225-277). London: Cambridge University Press.

Gentner, D., \& Toupin, C. (1986). Systematicity and surface similarity in the development of analogy. Cognitive Science, 10(3), 277-300. doi:10.1207/s15516709cog1003_2

Goswami, U. (1989). Relational complexity and the development of analogical reasoning. Cognitive Development, 4(3), 251268. doi:10.1016/0885-2014(89)90008-7

Goswami, U., \& Brown, A. L. (1990a). Melting chocolate and melting snowmen: Analogical reasoning and causal relations. Cognition, 35(1), 69-95. doi:0.1016/0010-0277(90)90037-k

Goswami, U., \& Brown, A. L. (1990b). Higher-order structure and relational reasoning: Contrasting analogical and thematic relations. Cognition, 36(3), 207-226. doi:10.1016/00100277(90)90057-q

Halford, G. S. (1993). Children's understanding: The development of mental models. Hillsdale, NJ: Erlbaum.

Halpern, E., Corrigan, R., \& Aviezer, O. (1983). In, on, and under: Examining the relationship between cognitive and language skills. International Journal of Behavioral Development, 6(2), 153-166. doi:10.1177/016502548300600203

Holyoak, K. J., Junn, E. N., \& Billman, D. O. (1984). Development of analogical problem-solving skill. Child Development, 55(6), 2042-2055. doi:10.2307/1129778

Holyoak, K. J., \& Thagard, P. (1995). Mental leaps: Analogy in creative thought. Cambridge, MA: MIT Press.

Huttenlocher, J., \& Levine, S. C. (1990). Primary test of cognitive skills. Monterey, CA: CTB/McGraw-Hill.

Johnston, J., \& Slobin, D. I. (1979). The development of locative expressions in English, Italian, Serbo-Croatian and Turkish. Journal of Child Language, 6(3), 529-545. doi:10.1017/ s030500090000252x

Kadir, T., \& Brady, M. (2001). Saliency, scale and image description. International Journal of Computer Vision, 45(2), 83-105.

Kaminski, J. A., \& Sloutsky, V. M. (2010). Concreteness and relational matching in preschoolers. In S. Ohlsson \& R. Catrambone (Eds.), Proceedings of the XXXII Annual Conference of the Cognitive Science Society (pp. 335-340). Mahwah, NJ: Erlbaum.

Loewenstein, J., \& Gentner, D. (2005). Relational language and the development of relational mapping. Cognitive Psychology, 50, 315-353. doi:10.1016/j.cogpsych.2004.09.004

Maintenant, C., Blaye, A., \& Paour, J.-L. (2011). Semantic categorical flexibility and aging: Effect of semantic relations on maintenance and switching. Psychology and Aging, 26(2), 461-466. doi:10.1037/a0021686 
Mandler, J. M. (2005). How to build a baby III: Image-schemas and the transition to verbal thought. In B. Hampe (Ed.), From perception to meaning: Image schemas in cognitive linguistics (pp. 137-164). Berlin: Mouton de Gruyter. doi:10.1515/9783110197532.2.137

Meints, K., Plunkett, K., Harris, P. L., \& Dimmock, D. (2002). What is 'on' and 'under' for 15-, 18- and 24-month-olds? Typicality effects in early comprehension of spatial prepositions. British Journal of Developmental Psychology, 20(1), 113-130. doi:10.1348/026151002166352

Park, Y. (2015). The impact of object type on the spatial analogies in Korean preschool children (Unpublished doctoral dissertation). Cornell University, New York.

Park, Y., \& Casasola, M. (2015). Plain or decorated? Object visual features matter in infant spatial categorization. Journal of Experimental Child Psychology, 140, 105-119. doi:10.1016/ j.jecp.2015.07.002

Park, Y., \& Casasola, M. (2017). The impact of object type on the spatial analogies in Korean preschoolers. Cognitive Psychology, 94, 53-66. doi:10.1016/j.cogpsych.2017.02.001

Pellegrino, J. W. (1985). Inductive reasoning ability. In R. J. Sternberg (Ed.), Human abilities: An information-processing approach (pp. 195-225). New York: W. H. Freeman.

Richland, L. E., Morrison, R. G., \& Holyoak, K. J. (2006). Children's development of analogical reasoning: Insights from scene analogy problems. Journal of Experimental Child Psychology, 94, 249-273. doi:10.1016/j.jecp.2006.02.002

Savic, O., Thierry, G., \& Ković, V. (2020). Conceptual relation preference: A matter of strategy or one of salience? Acta Psychologica, 204. doi:10.1016/j.actpsy.2020.103018

Scheuner, N., Bonthoux, F., Cannard, C., \& Blaye, A. (2004). The role of associative strength and conceptual relations in matching tasks in 4- and 6-year-old children. International Journal of Psychology, 39(4), 290-304. doi:10.1080/00207570344000394

Simms, N. K., Frausel, R. R., \& Richland, L. E. (2018). Working memory predicts children's analogical reasoning. Journal of Experimental Child Psychology, 166, 160-177. doi:10.1016/ j.jecp.2017.08.005

Son, J. Y., Smith, L. B., \& Goldstone, R. L. (2011). Connecting instances to promote children's relational reasoning. Journal of Experimental Child Psychology, 108(2), 260-277. doi:10.1016/ j.jecp.2010.08.011

Starr, A., Vendetti, M. S., \& Bunge, S. A. (2018). Eye movements provide insight into individual differences in children's analogical reasoning strategies. Acta Psychologica, 186, 1826. doi:10.1016/j.actpsy.2018.04.002

Sternberg, R. J., \& Gardner, M. K. (1983). Unities in inductive reasoning. Journal of Experimental Psychology: General,
112(1), 80-116. doi:10.1037/0096-3445.112.1.80

Thibaut, J., \& French, R. M. (2016). Analogical reasoning, control and executive functions: A developmental investigation with eye-tracking. Cognitive Development, 38, 10-26. doi:10.1016/j.cogdev.2015.12.002

Thibaut, J.-P., French, R., \& Vezneva, M. (2010). The development of analogy making in children: Cognitive load and executive functions. Journal of Experimental Child Psychology, 106(1), 1-19. doi:10.1016/j.jecp.2010.01.001

Tomasello, M. (1987). Learning to use prepositions: A case study. Journal of child Language, 14(1), 79-98. doi:10.1017/ s0305000900012745

Tunteler, E., \& Resing, W. C. M. (2002). Spontaneous analogical transfer in 4-year-olds: A microgenetic study. Journal of Experimental Child Psychology, 83(3), 149-166. doi:10.1016/ s0022-0965(02)00125-x

van Rullen, R. (2003). Visual saliency and spike timing in the ventral visual pathway. Journal of Physiology-Paris, 97(2-3), 365-377. doi:10.1016/j.jphysparis.2003.09.010

Vosniadou, S. (1989). Analogical reasoning as a mechanism in knowledge acquisition: A developmental perspective. In S. Vosniadou \& A. Ortony (Eds.), Similarity and analogical reasoning (pp. 413-437). Cambridge, MA: Cambridge University Press.

Waxman, S. R., \& Namy, L. L. (1997). Challenging the notion of a thematic preference in young children. Developmental Psychology, 33(3), 555-567. doi:10.1037/00121649.33.3.555

\section{In Korean}

Chang-Song, Y.-K. (2004). Early lexical development of Korean infants: 18 -36 months. The Korean Journal of Developmental Psychology, 17(4), 91-105.

Kim, S.-I. (2006). The development of analogical reasoning and creativity in preschoolers. The Journal of Child Education, 15(2), 81-100.

\section{ORCID}

Youjeong Park http://orcid.org/0000-0001-8989-3818 